\title{
Analysis of Telecommunication Tower with Different Bracing System
}

\author{
AkashD. Pathrikar ${ }^{1}$, Prof.L. G. Kalurkar ${ }^{2 *}$ \\ ${ }^{1}$ PG Student, Jawaharlal Nehru Engineering College, BAMU University, Aurangabad (M.S), 431003, India \\ ${ }^{2}$ Asst. Prof. Civil Engg. Department, Jawaharlal Nehru Engineering College, BAMU University, Aurangabad
}

(M.S), 431003, India

\begin{abstract}
Due to the high increase in the telecommunication business, number of buildings carrying a roof top tower has been increased rapidly. Most of the building were not originally designed to carry a roof top tower, but later converted to carry roof top towers due to the changed requirements. In the present work an attempt has been made to study the behavior of buildings with roof top tower in the event of an Earth Quake using STAAD pro. A typical residential building is considered for the analysis. Three towers with height $9 \mathrm{~m}, 18 \mathrm{~m}$, and $27 \mathrm{~m}$ is considered for the study. The building is analyzed by using different types of bracing system for respective heights.Telecommunication towers are categorized among the tallest man-made structures and can be found standing high on every parts of the globe with different heights and purposes. Towers are the tall steel framework construction used for different purposes such as communication tower, radio transmission, power transmission air traffic controls etc. The bracing members are arranged in many forms, which carry solely tension, or alternatively tension and compression. Towers are subjected to gravity loads and horizontal loads. The higher the structure, the more it is exposed to lateral loads such as wind load, since it has higher tendency to sway. If the bracing is weak, the compression member would buckle which leads to failure of the tower. A comparative seismic study between buildings with roof top towers is done to find out the most effective bracing system in the form of deflection.
\end{abstract}

Keywords: Bracing system, model analysis, response reduction factor, telecommunication tower, wind analysis, zone parameter.

\section{Introduction}

The Indian telecom service business is the fastest growing one in the world, with over seven million mobile subscribers being added every month. This expanding base possesses challenges to mobile operators in terms of augmenting and upgrading infrastructure to maintain to quality of services. A rapidly increasing subscriber base and a more stringent spectrum allocating regime may create a higher requirement of tower sites for operators to accommodate more subscribers. Hence it became a costly and tedious task to identify sufficient land for construction of towers. This led to the extensive use of the rooftop of multi-storeyed buildings for installing communication towers. However many of these buildings were not designed to take care of tower load, particularly under earthquake conditions. Communication towers act as vertical trusses and resists wind load by cantilever action. The bracing members are arranged in many forms, which carry solely tension, or alternatively tension and compression. The bracing is made up of crossed diagonals, when it is designed to resist only tension. Based on the direction of wind, one diagonal takes all the tension while the other diagonal is assumed to remain inactive. Tensile bracing is smaller in cross-section and is usually made up of a back-to back channel or angle sections. The tapered part of the tower is advantageous with regard to the bracing, as it reduces the design forces. The greater the height of the tower, greater will be the distance it can transmit radio signals. Communication Towers are classified as three categories that are guyed masts, monopole, and self-supporting tower. The structure engineer faces the challenging job designing and constructing telecommunication towers to support antenna loads, platform as well as steel ladder loads in throughout the world through still regimens to be high intensity winds (HIW). The major problem face is the difficulty in estimating wind loads as they are based on probabilistic approach. Self-supporting towers are generally preferred since they require less base area. Towers are subjected to gravity loads and horizontal loads. The bracing behave as struts, when it is designed to take compression. One of the most common arrangements is the cross bracing. The most significant dimension of a tower is its height. It's normally several times larger than the horizontal dimensions. The tapered part of the tower is advantageous with regard to the bracing, as are reduces design forces. Bracings hold the structure stable by transferring the loads sideways (not gravity, but wind or earthquake loads) down to the ground and are used to resist lateral loads, thereby preventing sway of the structure. Bracing increases the resistance of the structure against side sway or drift. The higher the structure, the more it is exposed to lateral loads such as wind load, since it has higher tendency to sway. If the bracing is weak, the compression member would buckle which leads to failure of the tower. Diagonal braces are efficient elements for developing stiffness and resistance to wind 
loads. There are different types of bracing systems in common use such as Single diagonal bracing, double diagonal (X-X) bracing, X-B bracing, XBX bracing, arch bracing, subdivided V bracing, diamond lattice system of bracing, $\mathrm{K}, \mathrm{Y}, \mathrm{W}, \mathrm{X}$ bracings etc.

\section{Tower Configurations}

The floor area, the number of floors and the shape of the building on which the rooftop tower is installed varies from building to building. Based on the survey of the buildings where rooftop towers were installed, it has been found that most of the towers are installed on commercial buildings and their structural dimensions vary within a range.Hence a typical commercial building frame with a long span and short span floor structure has been considered for the analysis.

\subsection{Analytical Analysis:}

\section{Modelling Approach}

The main objective of the analysis is to study the different forces acting on a building. The analysis is carried out in STAAD Pro software. Results of conventional structure i.e. slab, beam and column, steel tower structure for different heights are modelled for the different load combinations is analysed. The comparison is made between the steel tower structures for different heights.

3.2. Assumptions:

The following are the assumptions made:

The height of the building is kept as $45 \mathrm{~m}$ from ground these building is of 15 -storey. The height of one floor is of $3 \mathrm{~m}$ each. In this way 6 numbers of total models are analysed. The building is considered in seismic zone-II as per IS 1893:2002(Part-I).

\subsection{Group Properties:}

The different components of conventional R.C.C structure:

\begin{tabular}{|l|l|}
\hline Size of Column & $230 X 380 \mathrm{~mm}$ \\
\hline Size of Beam & $230 X 500 \mathrm{~mm}$ \\
\hline Slab Thickness & $150 \mathrm{~mm}$ \\
\hline External Wall & $230 \mathrm{~mm}$ \\
\hline Internal Wall & $180 \mathrm{~mm}$ \\
\hline Parapet Wall & $150 \mathrm{~mm}$ \\
\hline Grade of Concrete & M20 \\
\hline Grade of Steel & $\mathrm{Fe} 415$ \\
\hline
\end{tabular}

The different components of Steel Tower structure:

\begin{tabular}{|l|l|l|l|l|}
\hline $\begin{array}{l}\text { Sr. } \\
\text { No. }\end{array}$ & $\begin{array}{l}\text { Tower } \\
\text { Height }\end{array}$ & $\begin{array}{l}\text { Vertical } \\
\text { Section }\end{array}$ & $\begin{array}{l}\text { Horizontal } \\
\text { Section }\end{array}$ & $\begin{array}{l}\text { Inclined } \\
\text { Section }\end{array}$ \\
\hline 1. & $9 \mathrm{~m}$ & ISA200x200x25 & ISA200x200x25 & ISA150x150x10 \\
\hline 2. & $18 \mathrm{~m}$ & ISA200x200x25 & ISA200x200x25 & ISA150x150x10 \\
\hline 3. & $27 \mathrm{~m}$ & ISA200x200x25 & ISA200x200x25 & ISA150x150x10 \\
\hline
\end{tabular}

\subsection{Description of Loading:}

The loading of the buildings is considered as per following calculations:

1. Dead Loads:

i. Wall load with $230 \mathrm{~mm}$ thickness $=3 \times 1 \times 0.23 \times 18=12.42 \mathrm{kN} / \mathrm{m}$.

ii. Wall load with $180 \mathrm{~mm}$ thickness $=3 \times 1 \times 0.18 \times 18=9.72 \mathrm{kN} / \mathrm{m}$

iii. Wall load with $150 \mathrm{~mm}$ thickness $=1 \times 1 \times 0.15 \times 18=2.7 \mathrm{kN} / \mathrm{m}$

iv. Weight of the slab having thickness $150 \mathrm{~mm}=0.15 \times 1 \times 1 \times 25=3.75 \mathrm{kN} / \mathrm{m} 2$.

v. Self-weight of building is automatically considered by the STAAD Pro-2007 software.

2. Live Load:

The live load of $3 \mathrm{kN} / \mathrm{m} 2$ and floor finish of $1 \mathrm{kN} / \mathrm{m} 2$ is considered on the buildings.

3.5. Loading Combination:

The different loading combinations for the analysis of the building and tower considered are:

1. Dead Load (D.L.)

2. Live Load (L.L.)

3. Earthquake Load

\section{Analytical Approach And Design}

STAAD stands for structural Analysis and Design. It is one of the software applications created to help structural engineers automate their tasks, to remove the tedious and long procedure of the manual methods. It covers the steps to be followed to produce the structural analysis and design of concrete and steel. STAAD Pro 
is the professional's choice for steel, concrete, timber, aluminium and cold-formed steel design of low and highrise buildings, culverts, petrochemical plants, tunnels, bridges, piles and much more. The versatility of STAAD Pro makes it the choice of most leading engineering consultancies, design and construction professionals. STAAD Pro features a state-of-the-art users interface, visualization tools, powerful analysis and design engine with advanced finite element and dynamic capabilities. The commercial version STAAD Pro is one of the most widely used structural analysis and design software. It supports several steel, concrete and timber design codes. It can make use of various forms of analysis from the traditional 1st order static analysis, 2nd order p-delta analysis, geometric non-linear analysis or a buckling analysis. It can also make use of various forms of dynamic analysis from modal extraction to time history and response spectrum analysis. Additionally STAAD Pro has added direct links to applications such as RAM Connection and STAAD.

The basic three activities which are to be carried out to achieve the goal are:

1. Model generation

2. The calculations to be obtain the analysis results

3. Result verification.

The overall procedure of the performance analysis is:

1. The basic building model.

2. The supports, properties and materials for the required structures are assigned and entered.

3. The size of the members.

4. Load assigning.

5. At last run analysis is done and generated out file is taken.

6. Results are compared.

\subsection{Model Creation:}

The basic model considered is a $\mathrm{G}+15$ storey reinforced cement concrete building with communication tower resting on it with different types of bracing such as $\mathrm{X}, \mathrm{K}$ bracing. For these structures seismic and wind analyses is carried out and find the economical bracing system in the form of displacement. The typical configuration of towers considered for present study is shown in figure 1,2 and 3.

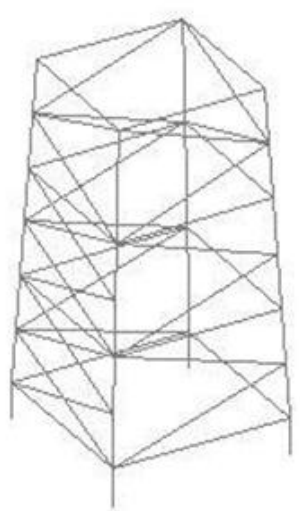

Fig. 1- 9m Tower

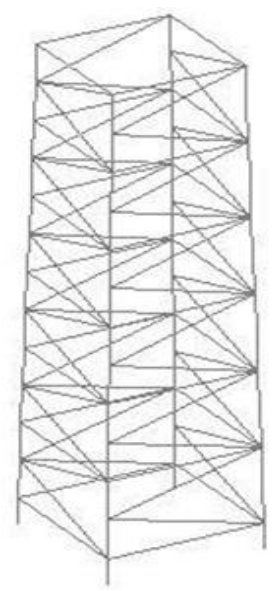

Fig. 2- 18m Tower 


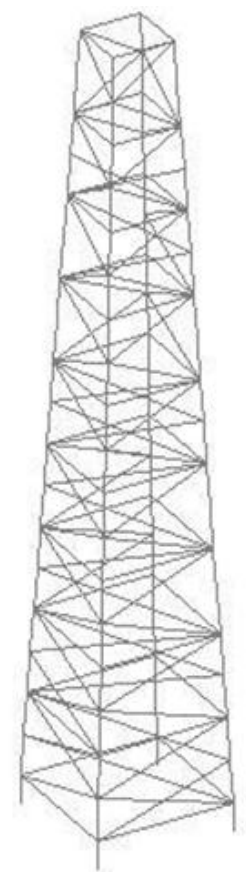

Fig. 3- 27m Tower

\section{Results}

The analysis and design is done by using software STAAD Pro. The models of different heights of tower resting on $\mathrm{G}+15$ building with different bracing system are compared. These towers are compared to find most effective bracing system in the form of deflection. The seismic analysis of $\mathrm{G}+15$ building with tower resting on it, is carried out. The wind analysis is carried out for the telecommunication tower resting on G+15 building with considering the seismic analysis of the building. Following results are obtained:

\begin{tabular}{|c|c|c|c|c|}
\hline $\begin{array}{l}\text { BUILDING } \\
\text { HEIGHT }\end{array}$ & $\begin{array}{l}\text { TOWER } \\
\text { HEGHT }\end{array}$ & $\begin{array}{l}\text { TYPE OF } \\
\text { BRACING }\end{array}$ & NODE DISPLACEMENT & BEAM DISPLACEMENT \\
\hline$(\mathrm{m})$ & $(\mathrm{m})$ & & $(\mathrm{mm})$ & $(\mathrm{mm})$ \\
\hline \multirow[t]{2}{*}{45} & \multirow[t]{2}{*}{9} & $\mathrm{~K}$ & 0.347 & 0.348 \\
\hline & & $\mathrm{X}$ & 0.317 & 0.316 \\
\hline \multirow[t]{2}{*}{45} & \multirow[t]{2}{*}{18} & $\mathrm{~K}$ & 1.797 & 1.797 \\
\hline & & $\mathrm{X}$ & 1.925 & 1.925 \\
\hline \multirow[t]{2}{*}{45} & \multirow[t]{2}{*}{27} & $\mathrm{~K}$ & 4.438 & 4.438 \\
\hline & & $\mathrm{X}$ & 4.959 & 4.96 \\
\hline
\end{tabular}

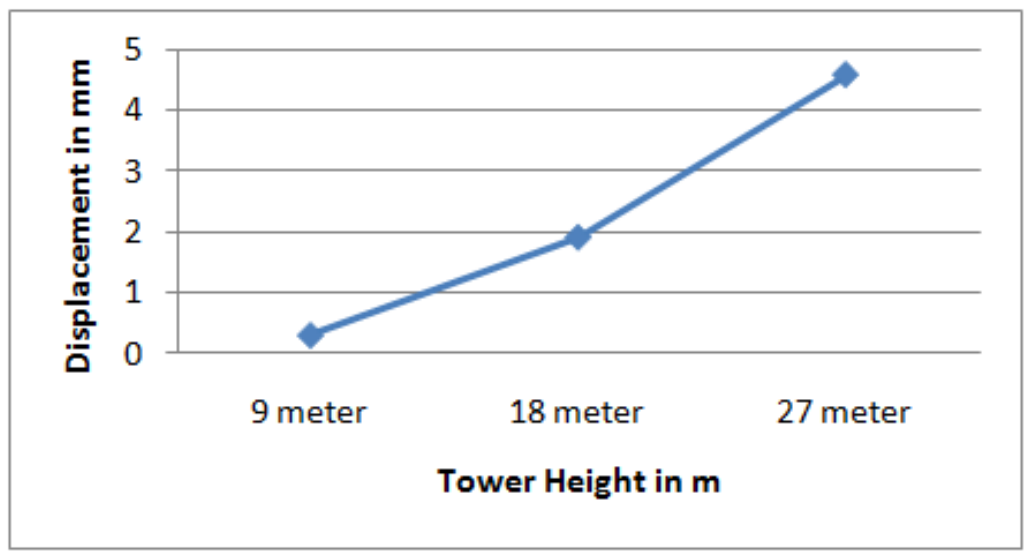

Fig. 4-Node Displacement X-Bracing 


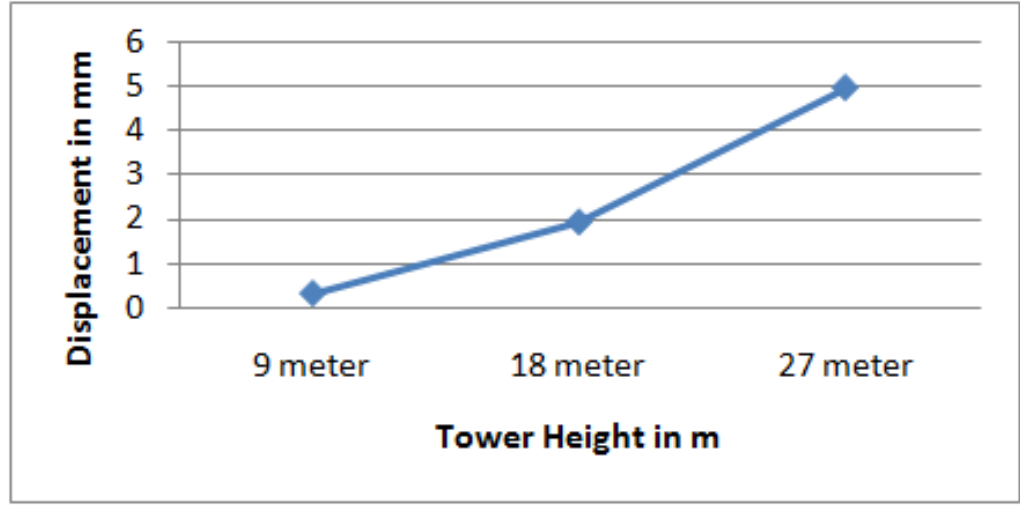

Fig. 5-Beam Displacement X-Bracing

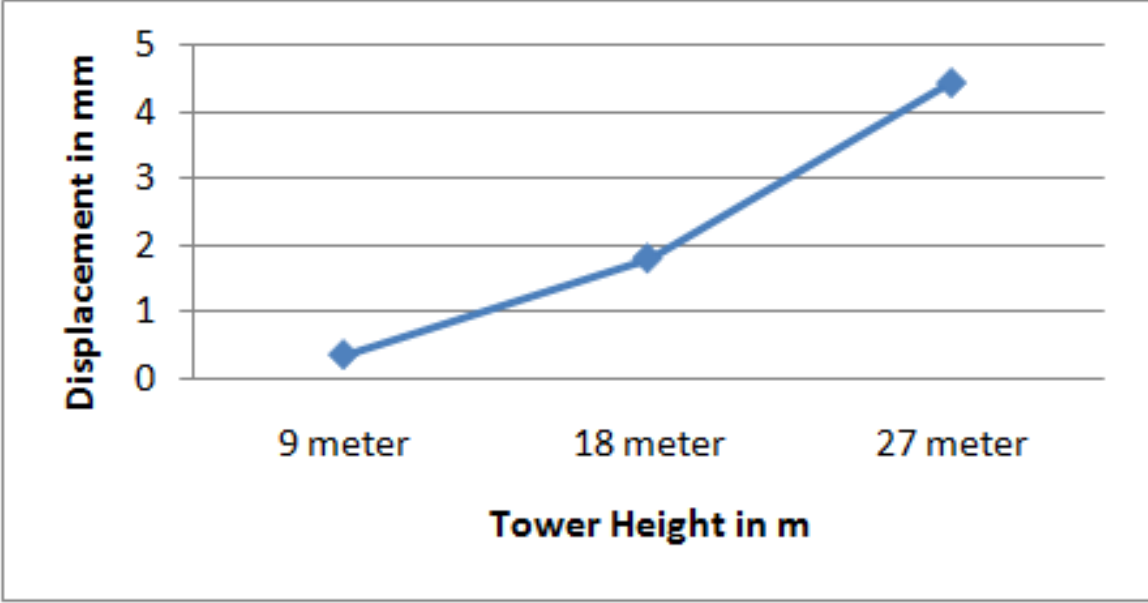

Fig. 6-Node Displacement K-Bracing

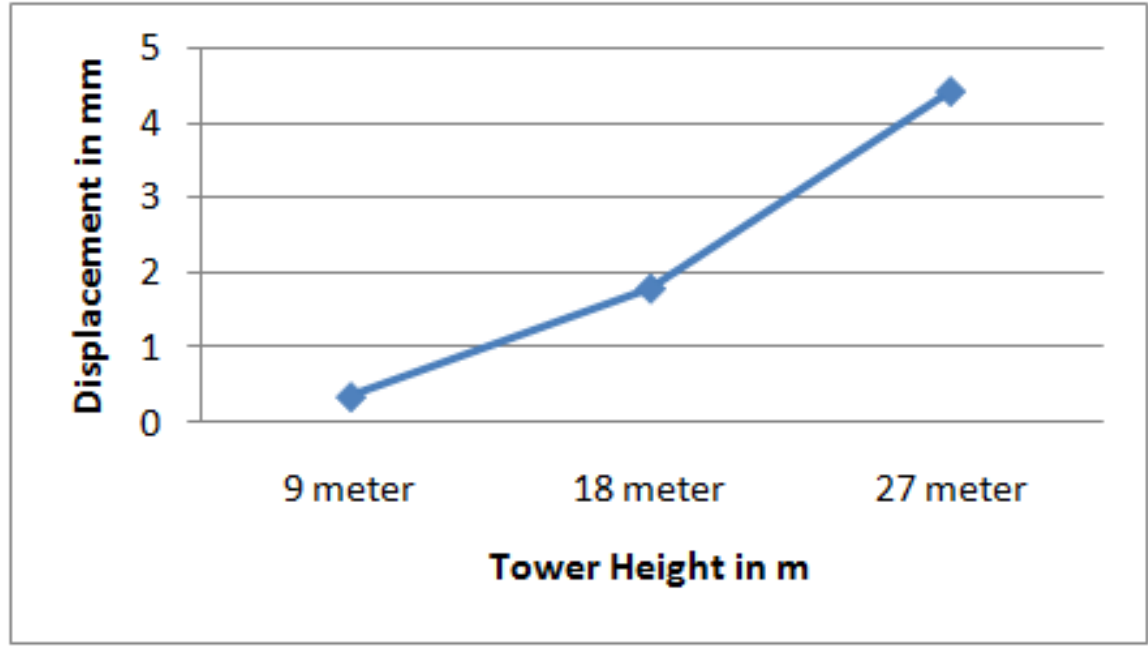

Fig. 7-Beam Displacement K-Bracing

\section{Conclusion}

The performance analysis shown in previous chapter helps to investigate the critical direction of the analysis of the G+15 RCC building with tower of different heights resting on building with different bracing system for the chosen problem. Following are the few conclusions drawn from the analysis results.

a. For a height of $9 \mathrm{~m}$ tower resting on the building $\mathrm{X}$ bracing is economical in the form of deflection at the top of the tower.

b. For a height of $18 \mathrm{~m}$ tower resting on the building $\mathrm{K}$ bracing is economical in the form of deflection at the top of the tower. 
c. For a height of $27 \mathrm{~m}$ tower resting on the building $\mathrm{K}$ bracing is economical in the form of deflection at the top of the tower.

d. From the above observation we can say that, the $\mathrm{X}$ bracing is economical up to the height of $55 \mathrm{~m}$ from above ground level.

e. And if the height increases then $\mathrm{X}$ bracing proves uneconomical and $\mathrm{K}$ bracing proves economical.

\section{References}

[1]. A. Jesumi and M. G. Rajendran "Optimal Bracing System for Steel Towers" karunya university, Coimbatore, volume.1 (2013).

[2]. Siddesha.H.’The analysis of microwave antenna tower”, S. I. T., Tumkur, Karnataka, India. Volume 1 (2010).

[3]. Selaraj.M. Kulkarni.S.M. Ramesh Babu. R "Structural evaluation of FRP pultruded sections in overhead transmission line tower" NITK, Bangalore, volume2, India. (2012).

[4]. V.Lakshi and etal "Study on performance of $220 \mathrm{KV}$ M/C MA tower due to wind" JNT University, Kakinada, volume 3,india.(2011).

[5]. UmeshS.Salunke and YuwarajM.Ghugal "Analysis and Design of three Legged double circuit transmission tower" Bauhaus university Weimar, volume.1 (2013).

[6]. Vinay R.B, Ranjith.A, Bharath.A”Optimization of Transmission Line Towers; P-Delta analysis" AIT, Chikmagalur, Karnataka, India. Vol. 3, Issue 7, July 2014.

[7]. Richa Bhatt, VipulPrakash, A.D.Pandey"Influence of modelling in the response of steel lattice mobile tower under wind loading"Volum2 (2013).

[8]. Khalied A., WahabAbdalla A. Alsamad "Stress \& strain analysis of mobile tower crane using finite element", volume 11 (2014). 